\title{
BMJ Open Effect of exercise on abdominal fat loss in men and women with and without type 2 diabetes
}

\author{
Devon A Dobrosielski, ${ }^{1,2}$ Bethany Barone Gibbs, ${ }^{3}$ Sameer Chaudhari, ${ }^{2}$ \\ Pamela Ouyang, ${ }^{2}$ Harry A Silber, ${ }^{2}$ Kerry J Stewart ${ }^{2}$
}

To cite: Dobrosielski DA, Barone Gibbs B, Chaudhari S, et al. Effect of exercise on abdominal fat loss in men and women with and without type 2 diabetes. BMJ Open 2013;3:e003897.

doi:10.1136/bmjopen-2013003897

- Prepublication history for this paper is available online. To view these files please visit the journal online (http://dx.doi.org/10.1136/ bmjopen-2013-003897)

Received 27 August 2013 Revised 14 October 2013 Accepted 15 October 2013

\section{CrossMark}

${ }^{1}$ Department of Kinesiology, Towson University, Towson, Maryland, USA

${ }^{2}$ Division of Cardiology, Department of Medicine, The Johns Hopkins School of Medicine, Baltimore, Maryland, USA

${ }^{3}$ Department of Health and Physical Activity, University of Pittsburgh, Pittsburgh, Pennsylvania, USA

Correspondence to Dr Devon A Dobrosielski; ddobrosielski@towson.edu

\section{ABSTRACT}

Objective: To examine the effect of exercise on abdominal adipose tissue in adults with and without type 2 diabetes mellitus (T2DM).

Design: Post hoc analysis of two randomised controlled trials.

Setting: Outpatient secondary prevention programme in Baltimore, Maryland, USA.

Participants: 97 men and women with prehypertension, stage 1 or medically controlled hypertension. $49 \%$ of the sample was also diagnosed with T2DM.

Intervention: All participants completed a 26-week (6.5 months) supervised aerobic and resistance exercise programme following American College of Sports Medicine guidelines.

Primary and secondary outcome measures: The main outcomes in this post hoc analysis were total abdominal adipose tissue (TAT), subcutaneous adipose tissue (SAT) and visceral adipose tissue (VAT) measured by MRI. Secondary outcomes were to determine whether the magnitude of abdominal fat change differed by diabetes status in men and women and to identify the predictors of change in abdominal fat distribution with exercise.

Results: Overall, participants (mean age $61 \pm 6$ years; $45 \%$ women) significantly improved peak oxygen uptake by $15 \%(p<0.01)$ and reduced weight by $2 \%(p<0.01)$. No change in SAT was observed after training. The reduction in VAT following exercise was attenuated in participants with T2DM $(-3 \%)$ compared with participants who were non-T2DM $(-18 \%, p<0.001$ for the difference in change). The magnitude of VAT loss was associated with a decrease in body weight $(r=0.50$, $p<0.001)$. After adjustment for weight change using regression analysis, diabetes status remained an independent predictor of the change in VAT.

Conclusions: Although participants with and without T2DM attained an exercise training effect as evidenced by increased fitness, VAT was unchanged in T2DM compared to those without T2DM, suggesting that these individuals may be resistant to this important benefit of exercise. The strategies for reducing cardiovascular disease risk in T2DM may be most effective when they include a weight loss component.

Clinical Trials Registration: Clinicaltrials.gov Registry NCT00212303.

\section{Strengths and limitations of this study}

- Use of a large dataset that included overweight/ obese adults with and without type 2 diabetes mellitus.

- Use of imaging techniques to assess abdominal fat content.

- Potential for bias due to the fact that our primary independent variable (diabetes status) corresponded directly to two separate clinical trials.

\section{INTRODUCTION}

In 2005, the Sugar, Hypertension and Physical Exercise Trial (SHAPE2) was launched to determine the impact of 6 months of supervised exercise training without dietary weight loss on resting blood pressure in persons with type 2 diabetes mellitus (T2DM) and untreated suboptimal blood pressure or treated hypertension. ${ }^{1}$ While exercise improved glycaemic control and fitness, it had no effect on blood pressure or improvement in the indices of vascular function, ${ }^{12}$ raising questions about the efficacy of exercise programmes for influencing the course of cardiovascular disease morbidity in those with T2DM.

We acknowledge that the accumulation of abdominal adipose tissue, particularly visceral adipose tissue (VAT), is associated with insulin resistance $^{3}$ and atherogenic abnormalities ${ }^{4} 5$ that may contribute to an increased risk of cardiovascular events. ${ }^{6}$ Exercise has been shown to reduce VAT in obesity, independent of weight loss. ${ }^{7-13}$ There is also evidence that aerobic $^{12-14}$ and aerobic combined with resistance exercise ${ }^{15}$ promotes abdominal fat loss in T2DM, but only one of these studies ${ }^{12}$ examined the abdominal fat loss with exercise in participants who were non-T2DM compared to men with T2DM. We hypothesised that, because of more significant derangements in glucose and fat metabolism, obese patients with T2DM may have an attenuated 
reduction in abdominal fat in response to exercise ${ }^{16}$ compared with their obese counterparts, which may explain, in part, a decreased benefit on cardiovascular disease risk.

Accordingly, the aim of the current post hoc analysis was to examine the effect of exercise training on total abdominal fat and compartmental abdominal fat in men and women with and without T2DM. Additional aims were to determine whether the magnitude of abdominal fat change differed by diabetes status in men and women and to identify the predictors of change in abdominal fat distribution with exercise.

\section{METHODS}

We combined the data from two previously conducted clinical trials, the Senior Hypertension and Physical Exercise Study (SHAPE1; 1999-2004) and the Sugar Hypertension and Physical Exercise Study (SHAPE2; 2005-2010). Comprehensive descriptions of the interventions, methodologies and main findings from these studies have been published elsewhere. ${ }^{1}{ }^{17}$ Briefly, in both trials, men and women were randomised to 6 months of supervised exercise training or to a control condition that received no exercise intervention. The present post hoc analysis examines the data among those individuals who were randomised to and successfully completed the 6-month exercise interventions. All participants provided a written informed consent.

\section{Setting and participants}

Men and women were enrolled in SHAPE1 based on the following criteria: (1) age (55-75 years); (2) prehypertension or stage 1 hypertension according to the guidelines of the Seventh Report of the Joint National Committee on Prevention, Detection, Evaluation and Treatment of High Blood Pressure (JNC 7) ${ }^{18}$; and (3) no T2DM at baseline. The inclusion criteria for SHAPE2 included: (1) men and women aged 40-65 years; (2) resting blood pressure between 120 and $159 \mathrm{~mm} \mathrm{Hg} / 85$ and $99 \mathrm{~mm} \mathrm{Hg}$ or use of at least one antihypertensive medication; and (3) non-insulin dependent T2DM meeting the 2003 American Diabetes Criteria. A comprehensive list of the exclusion criteria for these studies can be found elsewhere. ${ }^{17}$ All participants were free of known clinical cardiovascular disease and each participant completed a prestudy screening exercise stress test without evidence of ischaemia, high-grade arrhythmias or symptoms.

\section{Exercise intervention and study outcomes}

The same exercise intervention protocol was used in SHAPE1 and SHAPE2. Exercisers were scheduled to attend three sessions per week. The prescribed number of sessions was 78 ( 3 days a week for 26 weeks). If a participant had attended fewer than 62 sessions at 6 months $(80 \%)$ compliance, an extra month was allowed to get as close to 62 sessions as possible. Each session included resistance training and aerobic training components in accordance with previously published guidelines by the American College of Sports Medicine (ACSM). ${ }^{19}$ An exercise physiologist oversaw all sessions and ensured adherence to the exercise protocol. No attempt was made to control for diet, yet dietary data were obtained from a 3-day food record and were analysed using a software program (Nutritionist V; First DataBank, San Bruno, California, USA).

All study outcomes were measured at baseline and following the 6-month intervention. Body weight and height were measured using standard procedures. Total fat mass, lean mass and percentage of body fat were determined using dual energy X-ray absorptiometry (DEXA; GE Lunar Prodigy; General Electric Medical Systems, Milwaukee, Wisconsin, USA). The images were all analysed using the same version of DEXA software (V.13). VAT, subcutaneous adipose tissue (SAT) and total abdominal adipose tissue volumes around the abdomen were measured from images obtained using an MRI system (Siemens Vision 1.5T; Siemens Medical Systems, Iselin, New Jersey, USA). Peak oxygen uptake was determined using a Bruce protocol on a treadmill with a Cardinal Health Vmax 229 Metabolic System (Cardinal Health Inc, San Diego, California, USA). Oxygen consumption $\left(\mathrm{VO}_{2}\right)$ peak is expressed as $\mathrm{VO}_{2}$ per $\mathrm{kg}$ total body weight per minute $(\mathrm{mL} / \mathrm{kg} / \mathrm{min})$.

\section{Statistical analysis}

Our primary aims in this analysis were to measure the impact of exercise training on abdominal fat and to examine the potential effect of T2DM on this change. Baseline differences and changes for all variables of interest between men and women with and without T2DM who completed the exercise intervention were analysed with one-way analysis of variance. To study whether the improvements in abdominal fat were related to changes in weight or fitness, we calculated Pearson product moment correlations between 6-month changes in abdominal fat outcomes and weight and $\mathrm{VO}_{2}$ peak and exercise volume. Linear regression models were used to examine whether sex, T2DM and (later) changes in weight were associated with differences in pretraining to post-training values for each of the dependent variables (SAT, VAT and TAT). All regression models were adjusted for baseline values of the dependent variable, age and race because of differences between SHAPE1 and SHAPE2 participants at baseline. Data analysis was performed using STATA V.10.1 (StataCorp LP, College Station, Texas, USA). Type 1 error rate was set at $\alpha=0.05$.

\section{RESULTS}

A total of 97 participants (49 non-T2DM and 48 T2DM) completed the exercise interventions. Of these, $45 \%$ (26 non-T2DM and 18 T2DM) were women. The combined sample consisted mainly of white $(78 \%)$ individuals. 
Table 1 Participant demographics baseline physical characteristics

\begin{tabular}{|c|c|c|c|c|c|c|c|}
\hline \multirow[b]{2}{*}{ Age, years } & \multicolumn{3}{|c|}{ T2DM $(n=48)$} & \multicolumn{3}{|c|}{ Non-T2DM $(n=49)$} & \multirow{2}{*}{$\frac{\text { p Value }}{<0.001}$} \\
\hline & 58 & \pm & 3 & 63 & \pm & 5 & \\
\hline \multicolumn{8}{|l|}{ Sex } \\
\hline Male & 30 & & $63 \%$ & 23 & & $47 \%$ & 0.124 \\
\hline Female & 18 & & $37 \%$ & 26 & & $53 \%$ & \\
\hline \multicolumn{8}{|l|}{ Race } \\
\hline White & 29 & & 60 & 47 & & 96 & $<0.001$ \\
\hline Black & 18 & & 39 & 1 & & 2 & \\
\hline Other & 1 & & 1 & 1 & & 2 & \\
\hline $\mathrm{BMI}, \mathrm{kg} / \mathrm{m}$ & 32.5 & \pm & 5.4 & 29.3 & \pm & 3.8 & 0.001 \\
\hline Waist circumference, $\mathrm{cm}$ & 102.3 & \pm & 11.6 & 93.4 & \pm & 11.7 & 0.001 \\
\hline Total body fat, \% & 37.1 & \pm & 7.9 & 38.2 & \pm & 8.8 & 0.539 \\
\hline Fat-free mass, kg & 56.9 & \pm & 11.1 & 47.4 & \pm & 10.7 & $<0.001$ \\
\hline Fat mass, kg & 36.2 & \pm & 11.3 & 31.2 & \pm & 9.1 & 0.017 \\
\hline $\mathrm{VO}_{2}$ peak, $\mathrm{mL} / \mathrm{kg} / \mathrm{min}$ & 22.5 & \pm & 5.6 & 24.3 & \pm & 5.2 & 0.099 \\
\hline
\end{tabular}

Data are presented as mean \pm SD or $n(\%)$.

$\mathrm{BMI}$, body mass index; T2DM, type 2 diabetes mellitus; $\mathrm{VO}_{2}$, oxygen consumption.

Participant demographics and physical characteristics at baseline for all completers according to diabetes status are shown in table 1 . Consistent with the selection criteria of each trial, participants with T2DM were younger, and had a higher body mass index and a larger waist circumference compared to those without T2DM, whereas baseline fitness levels and percentage total body fat were similar between T2DM and non-T2DM. A listing of the current medications taken by the T2DM group has been previously reported. ${ }^{1}$

Individuals with T2DM completed a mean \pm SD of $72 \pm 17$ of their prescribed 78 sessions $(92 \%)$, which was not different from the $70 \pm 6$ sessions $(90 \%)$ completed by the participants who were non-T2DM $(\mathrm{p}=0.471)$. However, the non-T2DM group expended more calories per session $(428 \pm 184 \mathrm{kcal})$ compared to those with T2DM $(298 \pm 99 \mathrm{kcal}, \mathrm{p}<0.001)$. There were no significant differences between the T2DM and non-T2DM groups for total daily energy intake at baseline (T2DM: 1984 \pm 658 kcal vs non-T2DM: $1924 \pm 708 \mathrm{kcal}, \mathrm{p}=0.673)$ or following the exercise intervention (T2DM: $1960 \pm 655 \mathrm{kcal}$ vs non-T2DM: $1946 \pm 589 \mathrm{kcal}, \mathrm{p}=0.916)$. Additional dietary data are available on request to the corresponding author.

Baseline values, absolute 6-month change and relative (\%) 6-month change in the primary outcomes of abdominal fat measurements, weight and fitness are expressed in table 2. Across the entire sample, $\mathrm{VO}_{2}$ peak was significantly increased from $23.5 \pm 5.5$ at baseline to $27.1 \pm 6.3 \mathrm{~mL} / \mathrm{kg} / \mathrm{min}$ at the end of the 6 -month intervention $(\mathrm{p}<0.001) . \mathrm{VO}_{2}$ peak values at baseline and 6 months were higher among individuals who were non-T2DM but similar improvements were observed across diabetes status and sex (table 2). At baseline and at 6 months, participants with T2DM reached similar levels of respiratory exchange ratio (RER; baseline: $1.07 \pm 0.06$; 6 months: $1.07 \pm 0.08, \mathrm{p}=0.98)$, indicating similar degrees of effort at both time points. This is reflective of a true training effect for cardiorespiratory fitness. For participants who were non-T2DM, RER at 6 months was lower compared with the baseline (baseline: $1.12 \pm 0.06 ; 6$ months $1.09 \pm 0.05, \mathrm{p}<0.01$ ), suggesting a potential reduction in effort in this group at follow-up.

We observed reduced body weight from $89.5 \pm 17.4$ to $87.2 \pm 17.4 \quad(\mathrm{p}<0.001)$ overall. However, women with T2DM lost more weight $(5 \%)$ than women without T2DM (2\%). In contrast, men with T2DM lost no weight, that is, less than the men without T2DM $(3 \%)$. Women with T2DM showed the greatest loss in weight of all subgroups. The greatest reduction in VAT was observed in men who were non-T2DM and was significantly greater than that seen in women who were non-T2DM. Both men and women with T2DM had significantly less VAT change after 6 months of exercise than those without T2DM. In contrast, the change in SAT did not differ across sex or diabetes status $(\mathrm{p}=0.447)$. Thus, as expected, non-T2DM showed the greatest change in TAT $(\mathrm{p}<0.032)$.

We combined the data from the 97 exercisers to evaluate the relationships between changes in adipose tissue depots, weight, $\mathrm{VO}_{2}$ peak and average energy expenditure per exercise session. We found that the reductions in abdominal adipose tissue were strongly related to each other ( $\mathrm{r}$ range $0.45-0.93$ ) and to weight loss ( $\mathrm{r}$ range $0.37-0.80$; table 3 ). Interestingly, while increased $\mathrm{VO}_{2}$ peak was correlated with reduced VAT $(\mathrm{r}=-0.21, \mathrm{p}=0.04)$ and TAT $(-0.25, \mathrm{p}<0.01)$ in the combined sample, the change in $\mathrm{VO}_{2}$ peak was related to the change in VAT $(-0.43(<0.01)$ among non-T2DM T2DM, but not in the subgroup with T2DM. Across the entire sample the metabolic cost expended per exercise session was not associated with the change in weight, or TAT and SAT. There was a trend for an association between the loss of the VAT and the metabolic cost expended per session $(\mathrm{r}=-0.18, \mathrm{p}=0.08)$. 
Table 2 Primary outcome variables at baseline and changes with exercise

\begin{tabular}{|c|c|c|c|c|c|}
\hline & $\begin{array}{l}\text { Men, non-T2DM } \\
(n=23) \\
\text { Mean } \pm S D\end{array}$ & $\begin{array}{l}\text { Men with T2DM } \\
(\mathrm{n}=30) \\
\text { Mean } \pm \text { SD }\end{array}$ & $\begin{array}{l}\text { Women, non-T2DM } \\
(\mathrm{n}=26) \\
\text { Mean } \pm S D\end{array}$ & $\begin{array}{l}\text { Women with T2DM } \\
(\mathrm{n}=18) \\
\text { Mean } \pm S D\end{array}$ & $\begin{array}{l}\mathbf{p} \\
\text { Value }\end{array}$ \\
\hline \multicolumn{6}{|l|}{$\overline{\text { SAT }}$} \\
\hline Baseline $\left(\mathrm{cm}^{2}\right)$ & $229 \pm 75^{a}$ & $339 \pm 112^{b}$ & $330 \pm 105^{b}$ & $445 \pm 156^{c}$ & $<0.001$ \\
\hline 6-month change $\left(\mathrm{cm}^{2}\right)$ & $-24 \pm 25$ & $-12 \pm 38$ & $-27 \pm 38$ & $-26 \pm 49$ & 0.447 \\
\hline 6-month change (\%) & $-10 \pm 11$ & $-3 \pm 10$ & $-9 \pm 14$ & $-4 \pm 11$ & 0.082 \\
\hline \multicolumn{6}{|l|}{ VAT } \\
\hline Baseline $\left(\mathrm{cm}^{2}\right)$ & $187 \pm 65^{a}$ & $177 \pm 73^{a}$ & $110 \pm 48^{b}$ & $120 \pm 42^{b}$ & $<0.001$ \\
\hline 6-month change $\left(\mathrm{cm}^{2}\right)$ & $-41 \pm 33^{a}$ & $-6 \pm 35^{b}$ & $-14 \pm 23^{b}$ & $-10 \pm 29^{b}$ & $<0.001$ \\
\hline 6-month change (\%) & $-23 \pm 17^{a}$ & $-2 \pm 18$ & $-13 \pm 17$ & $-4 \pm 23^{b}$ & $<0.001$ \\
\hline \multicolumn{6}{|l|}{ TAT } \\
\hline Baseline $\left(\mathrm{cm}^{2}\right)$ & $417 \pm 98^{a}$ & $541 \pm 154^{\mathrm{b}, \mathrm{c}}$ & $441 \pm 131^{\mathrm{a}, \mathrm{c}}$ & $591 \pm 185^{b}$ & $<0.001$ \\
\hline 6-month change $\left(\mathrm{cm}^{2}\right)$ & $-65 \pm 36^{a}$ & $-14 \pm 69^{b}$ & $-42 \pm 57$ & $-35 \pm 78^{b}$ & 0.032 \\
\hline 6 -month change (\%) & $-17 \pm 9^{a}$ & $-2 \pm 11^{b}$ & $-10 \pm 14$ & $-4 \pm 13^{b}$ & $<0.001$ \\
\hline \multicolumn{6}{|l|}{ Weight } \\
\hline Baseline (kg) & $90 \pm 11^{a}$ & $101 \pm 15^{a}$ & $75 \pm 13^{b}$ & $91 \pm 20^{a}$ & $<0.001$ \\
\hline 6-month change $(\mathrm{kg})$ & $-3 \pm 3$ & $-1 \pm 4^{a}$ & $-2 \pm 3$ & $-5 \pm 5^{\mathrm{b}}$ & 0.011 \\
\hline 6-month change (\%) & $-3 \pm 3$ & $-1 \pm 4^{a}$ & $-3 \pm 5$ & $-5 \pm 5^{b}$ & 0.009 \\
\hline \multicolumn{6}{|l|}{ Lean mass } \\
\hline Baseline (kg) & $57.7 \pm 5.5^{a}$ & $63.1 \pm 7.9^{b}$ & $38.3 \pm 2.9^{c}$ & $46.5 \pm 7.3^{d}$ & $<0.001$ \\
\hline 6 -month change $(\mathrm{kg})$ & $1.9 \pm 1.3^{a}$ & $0.6 \pm 2^{\mathrm{b}, \mathrm{c}}$ & $1.2 \pm 1.5^{\mathrm{a}, \mathrm{c}, \mathrm{d}}$ & $0.2 \pm 1.8^{b, d}$ & 0.008 \\
\hline 6-month change (\%) & $3.3 \pm 2.2$ & $1 \pm 3$ & $3.1 \pm 3.9$ & $0.6 \pm 3.8$ & 0.008 \\
\hline \multicolumn{6}{|l|}{$\mathrm{VO}_{2}$ peak } \\
\hline Baseline (mL/kg/min) & $28 \pm 5^{a}$ & $25 \pm 5^{b}$ & $21 \pm 2^{c}$ & $18 \pm 3^{c}$ & $<0.001$ \\
\hline $\begin{array}{l}\text { 6-month change } \\
(\mathrm{mL} / \mathrm{kg} / \mathrm{min})\end{array}$ & $4 \pm 4$ & $3 \pm 3$ & $4 \pm 2$ & $3 \pm 2$ & 0.598 \\
\hline 6-month change (\%) & $16 \pm 14$ & $14 \pm 14$ & $18 \pm 10$ & $20 \pm 15$ & 0.464 \\
\hline
\end{tabular}

Linear regression models were used to examine the independent effects of sex and diabetes on absolute changes in abdominal adipose tissue, adjusted for baseline values of abdominal adipose tissue, age and race (table 4). In the initial model, for which T2DM was the reference group, non-T2DM status was associated with a negative regression coefficient for SAT, VAT and TAT. This can be interpreted as a greater decrease in the abdominal adipose tissue over the course of the exercise intervention in participants without T2DM versus participants with T2DM. However, these models had low overall $\mathrm{R}^{2}$ values $(12-22 \%)$ indicating a poor model fit. As we found that change in weight differed across diabetes status and sex (table 2), and change in weight was highly correlated with changes in abdominal fat (table 3), a second model (model 2) added baseline weight and weight change as covariates. In these models, fit was greatly improved with $\mathrm{R}^{2}$ increasing to $51-65 \%$. The greater weight change was independently and directly associated with change in SAT, VAT and TAT $(\mathrm{p}<0.001)$. Diabetes status remained an independent predictor for the change in VAT and TAT, again with non-T2DM being related to a greater decrease in abdominal fat with exercise versus T2DM, but diabetes status was no longer a significant predictor of SAT change. After adjusting for the effects of weight change, sex became an important predictor of VAT and TAT with men losing more relative to women over the course of the intervention.

\section{DISCUSSION}

The reduction in VAT among individuals with T2DM has ranged from $8 \%$ to $48 \%,{ }^{12-15} 20$ yet these previous studies were limited by small sample sizes with men or women only, or lacked a non-T2DM control. In the present analysis, we combined the data from two 6-month long clinical trials that included both men and women and therefore provide novel data that extend the current body of literature investigating the benefit of exercise on abdominal fat loss as measured by imagining techniques. Our results indicate that 6 months of exercise training led to an improved fitness, weight loss and a reduced total body fat among individuals with mild forms of hypertension with and without T2DM. However, further analysis revealed that on adjustment for baseline levels of fat and changes in weight, the magnitude of VAT loss was less in persons with T2DM. Thus, our key finding was that the presence of T2DM appears to limit the ability to lose VAT with exercise. While these 
Table 3 Unadjusted Pearson's correlations ( $r$ ( $p$ value)) of changes in the primary outcome variables in the sample and by T2DM status

\begin{tabular}{|c|c|c|c|c|c|}
\hline & SAT & VAT & TAT & Weight & $\mathrm{VO}_{2}$ \\
\hline \multicolumn{6}{|l|}{ SAT, $\mathrm{cm}^{2}$} \\
\hline T2DM & 1.00 & & & & \\
\hline Non-T2DM & 1.00 & & & & \\
\hline Combined sample & 1.00 & & & & \\
\hline \multicolumn{6}{|l|}{ VAT, $\mathrm{cm}^{2}$} \\
\hline T2DM & $0.62(<0.01)$ & 1.00 & & & \\
\hline Non-T2DM & $0.20(0.17)$ & 1.00 & & & \\
\hline Combined sample & $0.45(<0.01)$ & 1.00 & & & \\
\hline \multicolumn{6}{|l|}{ TAT, $\mathrm{cm}^{2}$} \\
\hline T2DM & $0.93(<0.01)$ & $0.84(<0.01)$ & 1.00 & & \\
\hline Non-T2DM & $0.78(<0.01)$ & $0.76(<0.01)$ & 1.00 & & \\
\hline Combined sample & $0.87(<0.01)$ & $0.81(<0.01)$ & 1.00 & & \\
\hline \multicolumn{6}{|l|}{ Weight, kg } \\
\hline T2DM & $0.80(<0.01)$ & $0.63(<0.01)$ & $0.77(<0.01)$ & 1.00 & \\
\hline non-T2DM & $0.67(<0.01)$ & $0.37(<0.01)$ & $0.68(<0.01)$ & 1.00 & \\
\hline Combined sample & $0.75(<0.01)$ & $0.50(<0.01)$ & $0.73(<0.01)$ & 1.00 & \\
\hline \multicolumn{6}{|l|}{$\mathrm{VO}_{2}, \mathrm{~mL} / \mathrm{kg} / \mathrm{min}$} \\
\hline T2DM & $-0.13(0.38)$ & $0.05(0.72)$ & $-0.09(0.56)$ & $0.07(0.66)$ & 1.00 \\
\hline Non-T2DM & $-0.27(0.06)$ & $-0.43(<0.01)$ & $-0.45(<0.01)$ & $-0.42(<0.01)$ & 1.00 \\
\hline Combined sample & $-0.20(0.05)$ & $-0.21(0.04)$ & $-0.25(<0.01)$ & $-0.13(0.22)$ & 1.00 \\
\hline
\end{tabular}

Data meeting statistical significance $(p<0.05)$ are presented as italics.

SAT, subcutaneous abdominal tissue; TAT, total adipose tissue; T2DM, type 2 diabetes mellitus; VAT, visceral adipose tissue; $\mathrm{VO}_{2}$ peak, oxygen consumption.

data contrast with the previous work on this topic, there are several points that deserve attention.

First, we employed an ACSM guidelines driven exercise prescription ${ }^{19}$ that consisted of aerobic training, three times per week of moderate-to-vigorous intensity (60-90\% HR max). By comparison, the aerobic intervention carried out by Lee et $a l^{12}$ in T2DM was more rigorous, consisting of $60 \mathrm{~min}$ of exercise for 5 days/ week. It has been firmly established that lipolysis in human fat cells is regulated by catecholamines interacting with stimulatory $\beta$-adrenergic receptors and inhibitory $\alpha$-adrenergic receptors. ${ }^{21} 22$ Aerobic exercise training improves SAT lipolysis by decreasing $\alpha$-adrenergic receptor antilipolytic activity. The impaired

Table 4 Six-month changes in abdominal fat parameters $\left(\mathrm{cm}^{2}\right)$ by diabetes status and sex, with and without adjustment for baseline and change in body weight

\begin{tabular}{|c|c|c|c|c|c|c|}
\hline & \multicolumn{3}{|l|}{ Model 1} & \multicolumn{3}{|c|}{$\begin{array}{l}\text { Model } 2 \text { (Model 1+baseline weight and } \\
\text { weight change) }\end{array}$} \\
\hline & $\bar{\beta}$ coefficient & $95 \% \mathrm{Cl}$ & p Value & 及 coefficient & $95 \% \mathrm{Cl}$ & p Value \\
\hline \multicolumn{7}{|l|}{$\mathrm{SAT}\left(\mathrm{cm}^{2}\right)$} \\
\hline Diabetes status (non-T2DM) & -23 & -4 to -14 & 0.020 & -10 & -24 to 3 & 0.126 \\
\hline Sex (men) & -2 & -20 to 15 & 0.802 & -8 & -29 to 12 & 0.412 \\
\hline Weight change $(\mathrm{kg})^{*}$ & - & - & & 28 & 23 to 34 & $<0.001$ \\
\hline $\mathrm{R}^{2}$ & $12 \%$ & & & $59 \%$ & & \\
\hline \multicolumn{7}{|l|}{$\operatorname{VAT}\left(\mathrm{cm}^{2}\right)$} \\
\hline Diabetes status (non-T2DM) & -29 & -14 to -43 & $<0.001$ & -18 & -6 to -30 & 0.005 \\
\hline Sex (men) & -3 & -17 to 12 & 0.690 & -17 & -29 to -5 & 0.007 \\
\hline Weight change $(\mathrm{kg})^{*}$ & - & - & & 18 & 12 to 23 & $<0.001$ \\
\hline $\mathrm{R}^{2}$ & $22 \%$ & & & $51 \%$ & & \\
\hline \multicolumn{7}{|l|}{ TAT $\left(\mathrm{cm}^{2}\right)$} \\
\hline Diabetes status (non-T2DM) & -62 & -31 to -94 & $<0.001$ & -43 & -22 to -64 & $<0.001$ \\
\hline Sex (men) & -11 & -37 to 16 & 0.428 & -49 & -76 to -23 & $<0.001$ \\
\hline Weight change $(\mathrm{kg})^{\star}$ & - & - & & 46 & 37 to 55 & $<0.001$ \\
\hline $\mathrm{R}^{2}$ & $16 \%$ & & & $65 \%$ & & \\
\hline
\end{tabular}

All models adjusted for baseline abdominal fat value, age and race.

*Weight change coefficient standardised to $1 \mathrm{SD}$ of weight change $(3.9 \mathrm{~kg})$.

SAT, subcutaneous adipose tissue; TAT, total abdominal tissue; T2DM, type 2 diabetes mellitus; VAT, visceral adipose tissue. 
ability of persons with T2DM in our study to lose VAT may relate to the reduced sensitivity of visceral adipocytes to catecholamines or a stronger $\alpha$-adrenergic-mediated response in these cells. Therefore, more vigorous and frequent exercise bouts and/or bouts of longer duration may be required in T2DM to sustain catecholamines at levels that result in a greater lipolysis in visceral adipocytes. That being said, we observed a small relationship between the metabolic cost per session and the loss of VAT that fell short of statistical significance. Of course, without measuring the catecholamine levels or the receptor activity in the present study this point remains speculative.

Second, consistent with ACSM guidelines our exercise intervention included whole body resistance training for 3 days/week. ${ }^{19}$ Prior work by Ormsbee $e t a l^{23}$ found a blunted lipolytic response to an acute bout of resistance exercise in obese men compared with lean men. They noted an increase in growth hormone $(\mathrm{GH})$ from the resting levels following the exercise bout in the lean participants, but no similar response among the obese participants. Since GH is an important regulator of lipolysis it may be that the inability to lose VAT by participants with T2DM in our study is related to diminished GH responses to resistance exercise. Interestingly, gains in fat-free mass among our T2DM cohort were also blunted compared with our non-T2DM group, which might also be suggestive of impaired release of GH. However, we are unaware of any studies that have addressed this hypothesis.

Third, although age was not an independent predictor of the change in VAT in our regression analyses, it could be that older age impairs the exercise-induced reductions in VAT. Indeed, Mourier $e t a l^{14}$ and Lee $e t a l^{12}$ observed a significant VAT loss in participants with T2DM who were much younger and achieved greater gains in fitness than the participants with T2DM enrolled in our study. Thus, if we again consider that $\beta$-adrenoceptor sensitivity to catecholamines is impaired in T2DM, ${ }^{24}$ this effect may be greater among older persons. ${ }^{25}$ Interestingly, however, compared to our non-T2DM group, our T2DM group was younger and fatter per inclusion criteria, and this would most likely have resulted in a greater abdominal fat reduction. The observation that they lost less despite these advantages means that any potential bias is probably underestimating our effect.

Fourth, individuals with early-stage T2DM are more likely to benefit from intensive lifestyle intervention, with regard to improvement in body weight, fitness, blood pressure, glycaemic control and lipids. ${ }^{26}$ We do not have specific data on the duration of diabetes diagnosis, but note that we excluded individuals who were taking insulin. Moreover, those enrolled in the intervention showed good glycaemic control at baseline. ${ }^{1}$ Both points suggest that our participants had a shorter duration of diabetes. Whether age or the stage of diabetes moderates the amount of fat lost with exercise warrants further examination.
While the disparities in VAT loss between our T2DM and non-T2DM groups are striking, examining the extent to which the inability to lose VAT in T2DM translates to poorer cardiovascular outcomes is beyond the scope of the current analysis, but an area for future investigation. Furthermore, we emphasise that recent guidelines recommend weight loss for all overweight or obese individuals who have or are at risk for diabetes. ${ }^{27}$ The most effective behavioural weight loss programmes incorporate dietary changes, and diet and exercise may be synergistic in achieving cardiovascular benefit. Moreover, we know from gastric bypass studies that extreme weight loss drastically improves or even cures T2DM. ${ }^{28}$ Thus, weight loss may potentiate the beneficial effects of exercise, and vice versa. The current findings do not detract from the above recommendation; rather, given that we found weight loss to independently predict the amount of VAT lost, our data help to reinforce these guidelines. Also, despite the negative finding related to the absence of VAT loss among our patients with T2DM, we underscore that the loss of abdominal fat among our older men who were non-T2DM was significant. Considering that obesity exacerbates the age-related decline in physical function in older adults, ${ }^{29}$ our data support the continued promotion of exercise among the elderly as a means to prevent reduced physical function with aging.

Several limitations of our study deserve comment. Our participants with T2DM were being prescribed a wide array of hypoglycaemic agents ${ }^{1}$ that may lead to weight gain or prevent weight loss. ${ }^{30}$ Exploring the interaction between exercise and these hypoglycaemic agents is an interesting one but the present study does not have sufficient statistical power to examine this. We acknowledge the inherent potential for bias when our primary independent variable (diabetes status) corresponded directly to the two separate clinical trials, which did have a few differences as we outlined in the Methods section. However, as also mentioned above, the exercise intervention was identical in both trials and the younger and more obese characteristics of the patients with T2DM would most likely introduce a conservative bias if any. Future research on this question within a single clinical trial population including participants with and without T2DM and appropriate controls could help address this limitation.

In conclusion, while exercise training improved fitness and reduced weight and total body fat among individuals with mild forms of hypertension with and without T2DM, the loss of VAT was less in individuals with T2DM compared to individuals who were non-T2DM. Importantly, this effect remained after controlling for the amount of weight lost, suggesting that the ability to improve body fat distribution (ie, lose VAT) with exercise, independent of weight change, is impaired by T2DM. The findings of this study should stimulate investigators to examine the effects of different exercise strategies on abdominal fat and to explore how to more effectively reduce VAT in individuals with T2DM, where a greater impact on cardiovascular disease outcomes is needed. 
Contributors PO, HAS and KJS made substantial contributions to the conception and design. DAD and BBG provided analysis and interpretation of data, and drafted the article. PO, HAS and KJS revised it critically for important intellectual content. DAD, BBG, PO, HAS and KJS approved the version published.

Funding This study was supported by grant R01HL59164 from the Heart, Lung and Blood Institute and R01DK62368 from the National Institute of Diabetes and Digestive and Kidney Diseases; National Institutes of Health (KJS); and by Grant Number UL1 RR 025005 from the National Center for Research Resources (NCRR), a component of the National Institutes of Health $(\mathrm{NIH})$, and NIH Roadmap for Medical Research. The studies were conducted at the Clinical Research Unit of the Institutes for Clinical and Translation Research at the Johns Hopkins Bayview Medical Center.

Competing interests None.

Ethics approval Johns Hopkins School of Medicine Institutional Review Board.

Provenance and peer review Not commissioned; externally peer reviewed.

Data sharing statement The manuscript is in compliance with US National Institutes of Health data sharing policies. Extra data are available by emailing ddobrosielski@towson.edu.

Open Access This is an Open Access article distributed in accordance with the Creative Commons Attribution Non Commercial (CC BY-NC 3.0) license, which permits others to distribute, remix, adapt, build upon this work noncommercially, and license their derivative works on different terms, provided the original work is properly cited and the use is non-commercial. See: http:// creativecommons.org/licenses/by-nc/3.0/

\section{REFERENCES}

1. Dobrosielski DA, Gibbs BB, Ouyang P, et al. Effect of exercise on blood pressure in type 2 diabetes: a randomized controlled trial. J Gen Intern Med 2012;27:1453-9.

2. Barone Gibbs B, Dobrosielski DA, Bonekamp S, et al. A randomized trial of exercise for blood pressure reduction in type 2 diabetes: effect on flow-mediated dilation and circulating biomarkers of endothelial function. Atherosclerosis 2012;224:446-53.

3. Despres JP. Is visceral obesity the cause of the metabolic syndrome? Ann Med 2006;38:52-63.

4. Cote M, Mauriege P, Bergeron J, et al. Adiponectinemia in viscera obesity: impact on glucose tolerance and plasma lipoprotein and lipid levels in men. J Clin Endocrinol Metab 2005;90:1434-9.

5. Lemieux I, Pascot A, Prud'homme D, et al. Elevated C-reactive protein: another component of the atherothrombotic profile of abdominal obesity. Arterioscler Thromb Vasc Biol 2001;21:961-7.

6. Despres JP, Lemieux I. Abdominal obesity and metabolic syndrome. Nature 2006;444:881-7.

7. Ross R, Dagnone D, Jones PJ, et al. Reduction in obesity and related comorbid conditions after diet-induced weight loss or exercise-induced weight loss in men. A randomized, controlled trial. Ann Intern Med 2000;133:92-103.

8. Ross R, Janssen I, Dawson J, et al. Exercise-induced reduction in obesity and insulin resistance in women: a randomized controlled trial. Obes Res 2004;12:789-98.

9. Irving BA, Davis CK, Brock DW, et al. Effect of exercise training intensity on abdominal visceral fat and body composition. Med Sci Sports Exerc 2008;40:1863-72.
10. Thomas EL, Brynes AE, McCarthy J, et al. Preferential loss of visceral fat following aerobic exercise, measured by magnetic resonance imaging. Lipids 2000;35:769-76.

11. Irwin ML, Yasui $Y$, Ulrich CM, et al. Effect of exercise on total and intra-abdominal body fat in postmenopausal women: a randomized controlled trial. JAMA 2003;289:323-30.

12. Lee S, Kuk JL, Davidson LE, et al. Exercise without weight loss is an effective strategy for obesity reduction in obese individuals with and without type 2 diabetes. J Appl Physiol 2005;99:1220-5.

13. Giannopoulou I, Ploutz-Snyder LL, Carhart R, et al. Exercise is required for visceral fat loss in postmenopausal women with type 2 diabetes. J Clin Endocrinol Metab 2005;90:1511-18.

14. Mourier A, Gautier J-F, Kerviler ED, et al. Mobilization of visceral adipose tissue related to the improvement in insulin sensitivity in response to physical training in NIDDM: effects of branched-chain amino acid supplements. Diabetes Care 1997;20:385-91.

15. Sigal RJ, Kenny GP, Boule NG, et al. Effects of aerobic training, resistance training, or both on glycemic control in type 2 diabetes: a randomized trial. Ann Intern Med 2007;147:357-69.

16. Lewis GF, Carpentier A, Adeli K, et al. Disordered fat storage and mobilization in the pathogenesis of insulin resistance and type 2 diabetes. Endocr Rev 2002;23:201-29.

17. Stewart KJ, Bacher AC, Turner KL, et al. Effect of exercise on blood pressure in older persons: a randomized controlled trial. Arch Intern Med 2005;165:756-62.

18. Chobanian AV, Bakris GL, Black HR, et al. The Seventh Report of the Joint National Committee on Prevention, Detection, Evaluation, and Treatment of High Blood Pressure: the JNC 7 report. JAMA 2003;289:2560-72.

19. Franklin BA. ACSM's guidelines for exercise testing and prescription. Philadelphia: Lippincott Williams \& Wilkins, 2000.

20. Jung JY, Han KA, Ahn HJ, et al. Effects of aerobic exercise intensity on abdominal and thigh adipose tissue and skeletal muscle attenuation in overweight women with type 2 diabetes mellitus. Diabetes Metab J 2012;36:211-21.

21. Galitzky J, Lafontan M, Nordenstrom J, et al. Role of vascula alpha-2 adrenoceptors in regulating lipid mobilization from human adipose tissue. J Clin Invest 1993;91:1997-2003.

22. Barbe $P$, Stich V, Galitzky J, et al. In vivo increase in beta-adrenergic lipolytic response in subcutaneous adipose tissue of obese subjects submitted to a hypocaloric diet. J Clin Endocrinol Metab 1997;82:63-9.

23. Ormsbee MJ, Choi MD, Medlin JK, et al. Regulation of fat metabolism during resistance exercise in sedentary lean and obese men. J Appl Physiol 2009;106:1529-37.

24. Lonnqvist $F$, Thome A, Nilsell $K$, et al. A pathogenic role of viscera fat beta 3-adrenoceptors in obesity. J Clin Invest 1995;95: 1109-16.

25. Lonnqvist $\mathrm{F}$, Nyberg $\mathrm{B}$, Wahrenberg $\mathrm{H}$, et al. Catecholamine-induced lipolysis in adipose tissue of the elderly. J Clin Invest 1990;85: 1614-21.

26. Wing RR. Long-term effects of a lifestyle intervention on weight and cardiovascular risk factors in individuals with type 2 diabetes mellitus: four-year results of the Look AHEAD trial. Arch Intern Med 2010;170:1566-75.

27. American Diabetes Association. Executive summary: standards of medical care in diabetes-2012. Diabetes Care 2012;35(Suppl 1): S4-10.

28. Cummings DE, Overduin J, Foster-Schubert KE. Gastric bypass for obesity: mechanisms of weight loss and diabetes resolution. J Clin Endocrinol Metab 2004;89:2608-15

29. Villareal DT, Banks M, Siener C, et al. Physical frailty and body composition in obese elderly men and women. Obes Res 2004;12:913-20.

30. Fonseca V. Effect of thiazolidinediones on body weight in patients with diabetes mellitus. Am J Med 2003;115(Suppl 8A):42S-8S. 